\section{MISOGINIA Y DEFENSA DE LAS DAMAS EN EL VIRREINATO PERUANO: LOS COLOQUIOS ENTRE DELIO Y CILENA EN LA MISCELÁNEA AUSTRAL (1602) DE DIEGO DÁVALOS}

\author{
BEATRIZ BARRERA \\ Universidad de Sevilla \\ bbarrera@us.es
}

Beatriz Barrera Parrilla

Doctora en Filología Hispánica y Profesora de Literatura Hispanoamericana en la Universidad de Sevilla, participa en Proyectos de Investigación del ámbito de la literatura colonial. Ha publicado estudios sobre poesía y narrativa hispánica contemporánea, sobre literatura colonial y sobre el imaginario cultural en la propaganda política del siglo XIX. Sus líneas prioritarias de investigación son actualmente los estudios coloniales y la poesía hispanoamericana contemporánea. Entre sus publicaciones cabe destacar las monografías Jaime Sabines: una poética entre el cuerpo y la palabra (2004) y Las lecturas del poeta (Otros estudios sobre Jaime Sabines) (2005).

\title{
RESUMEN
}

Diego Dávalos y Figueroa firma la primera Defensa de damas (Lima, 1603) que se publica en América. El poema es un colofón a un diálogo publicado un año antes bajo el título de Primera parte de la Miscelánea Austral. Esta obra se compone de cuarenta y cuatro coloquios entre Delio y Cilena, identificados plenamente con Diego Dávalos y su esposa Francisca de Briviesca. Se ha revisado el papel de la mujer y la consideración de lo femenino en este texto, contrastándolo con los modelos de la herencia cultural tras el Renacimiento. Entre las conclusiones se sugiere la posibilidad de que la esposa del poeta haya participado en la elaboración del texto más allá de inspirarlo.

Palabras clave: Dávalos y Figueroa - Miscelánea Austral - coloquios - damas - virreinato peruano.

\section{ABSTRACT}

The first defence of ladies on the American continent was a poem published in Lima, in 1603, by Diego Dávalos y Figueroa. Defensa de damas was written as a second part of the Miscelánea Austral (1602), an extensive dialogue where Delio and Cilena (the author Diego Dávalos and his wife Francisca de Briviesca) talk about multiple subjects, including love and ladies' qualities and behaviour.

This essay pays attention to female cultural roles in Davalos' works. It suggests the possibility that his wife had also taken part in his production.

Key words: Davalos y Figueroa, Miscelanea Austral, dialogues, women, colonial Peru.

La Miscelánea Austral de Diego Dávalos y Figueroa, impresa en Lima, en la Casa de Antonio Ricardo, consta de dos partes: la primera (1602) reúne cuarenta y cuatro coloquios que sostienen un caballero y su dama, Delio y
Cilena, que tratan de asuntos diversos, siendo el principal el amoroso; la segunda parte (titulada Defensa de damas, 1603) es un ambicioso colofón en verso de la primera, y en ella ya solamente tenemos la voz de Delio.
Misoginia y defensa de las damas

en el virreinato peruano: los coloquios entre Delio y Cilena en la Miscelánea Austral (1602) de Diego Dávalos

BEATRIZ BARRERA 

Con esta base médica para la naturaleza de la mujer justificando la dependencia del varón al que ha de estar sometida, los argumentos teológicos no encontraron dificultad en acoplarse a la idea de un sexo débil launque temible) y corruptible, culpable siempre, que encontraba en la Eva bíblica un icono efectivo de la misoginia. Su contrapunto, la virgen María (precisamente por ser virgen) no es capaz de redimir al género completo, más bien se presenta como horizonte o modelo, siempre sobrenatura e inalcanzable (Archer, 2001, pp. 26-30)

\footnotetext{
Misoginia y defensa de las damas en el virreinato peruano: los coloquios entre Delio y Cilena en la Miscelánea Austral (1602) de Diego Dávalos

BEATRIZ BARRERA
}

\section{La mujer en la Miscelánea Austral}

Para comprender el alcance del tratamiento de la mujer en una obra como la Miscelánea Austral y del gesto que supuso incluir en ella, por primera vez en el Nuevo Mundo, una Defensa de damas, se hace imprescindible ubicarla en el marco del debate sobre el matrimonio (y sobre el papel social de las mujeres) que propiciaba la aparición del estado moderno en Europa, junto con todas las utopías sobre gobierno, educación y orden político del Renacimiento, en que se educó el autor (Barrera, 2008).

Los coloquios de Dávalos son representativos de la última etapa del género de los diálogos con que la literatura didáctica renacentista más avanzada respondía a los tratados tradicionales sobre educación femenina y prolongaba la «querella de las mujeres» de los siglos anteriores (Barrera, 2008; Gómez, 1988; Rallo Gruss, 1996); resultan no obstante poco o nada innovadores a la hora de esgrimir razones contra la misoginia (Morant, 2006). Creemos que la expectativa que suscita el prólogo de la obra de Dávalos queda incumplida en su desarrollo dialogado y sobre todo en el verso (en la Defensa) por una endeblez debida a la carencia de modelos y de autoridades sólidas, ya que por lo general la defensa de las mujeres se había limitado durante siglos a matizar un saber científico, rara vez cuestionado, que hacía que la naturaleza femenina estuviera sometida a la masculina en toda circunstancia.

Los lugares comunes medievales en torno a lo femenino que siguen vigentes en la época de Dávalos (y él parece asumir a pesar de su actitud favorable a las damas) parten de Aristóteles y sus herederos, cuya ciencia hace de la mujer un hombre mutilado (masculus occasionatus), cuya fisonomía reproduce imperfectamente la del varón, con un esperma que carece del principio del alma, una menstruación venenosa y una temperatura interna inferior a la masculina, frialdad que impediría el desarrollo completo de los genitales hacia afuera y provocaría un exceso de humedad, solamente purgable mediante el coito. De ahí habría derivado uno de los más evidentes defectos femeninos: la histeria, en relación con la desmesura de su deseo del calor masculino, que no podría ser saciado, como recoge el conciso estudio preliminar que dedica Robert Archer a su bien escogida antología de textos medievales y de fuentes clásicas sobre Misogi- nia y defensa de las mujeres (2001, pp. 23-25). La misma desmesura se hacía extensible a otros aspectos de la vida como el dormir y el holgar, la glotonería, la codicia, la incontinencia verbal o la ira, apetitos que someten a la mujer en su racionalidad y la descalifican políticamente ${ }^{1}$. La tradición destaca un rasgo que sirve de freno a tanto exceso: la considerada natural vergüenza femenina, que desempeñará un papel fundamental en la Miscelánea, funcionando, tanto en boca de Delio como de Cilena, como principal indicativo de elegancia y decoro. La vergüenza es necesaria tanto para hombres como para mujeres: este matiz de simetría aproxima la Miscelánea Austral a una sensibilidad infrecuente donde los dos sexos comparten espacios morales. El texto parece atestiguar las negociaciones entre el poeta y su esposa en este sentido, si bien Dávalos nunca abandona su idea de la superioridad masculina.

La alabanza de las mujeres se había basado esencialmente en la negación de una identidad femenina: la virtud solamente resultará alcanzable a la mujer si renuncia a su condición para aproximarse a la del varón (no en vano es viril la etimología de virtus). Robert Archer (2001, p. 52) señala esto al hablar de un texto que debemos considerar para leer la obra de Dávalos: el Libro de las claras y virtuosas mujeres de Álvaro de Luna. El concepto lo encontramos sobre todo en la segunda parte de la Miscelánea, la Defensa en verso, que resulta tan decepcionante. A pesar del alarde humanista de Dávalos, de su impresionante despliegue de autoridades y fuentes clásicas e italianas (o tal vez precisamente por eso) tan sólo en algunos momentos de los coloquios de la Primera Parte de la Miscelánea entrevemos fisuras en esta estructura, que por lo general permanece escolástica. No debemos olvidar la corriente de pensamiento misogámica que partiendo de San Agustín continuarán otros padres de la iglesia, según la cual la virginidad o el celibato se venían entendiendo el estado natural de los seres humanos y una anticipación del ser angélico, de modo que toda relación matrimonial era considerada como una molestia, innecesaria para el hombre y degradante para la mujer (Archer, 2001, 30-33; Morant, 2002).

Es contra esta tradición que se escribe la Miscelánea en realidad; Dávalos no es tanto un defensor de la mujer como de la institución matrimonial. La preocupación por la mujer es 
para muchos autores del periodo inseparable de la preocupación por el matrimonio y la estructura familiar como pilares de la vida moderna, por eso la necesidad de orden y control impera sobre la voluntad de dignificación femenina y regula las concesiones. Del mismo modo que el matrimonio por amor tiene unas normas estrictas para desenvolverse sin que dañe los fundamentos de la sociedad, así la mujer es buena y se relaciona con el varón y con el mundo dentro de unas estrictas reglas de decoro, más rígidas a medida que se asciende en la escala social.

Hay un referente que resulta difícil soslayar cuando leemos su texto: los Coloquios de Erasmo sobre el matrimonio. Aunque Alicia de Colombí (1985, p. 95) no les concede relevancia frente a otros textos más importantes para la Miscelánea, lo cierto es que en cuanto a este asunto que nos ocupa resultan fundamentales para comprender la aportación de Dávalos, marcando el grado y punto de su apego y de su distanciamiento de los modelos.

En Proci et Virginis o El galán y la dama, coloquio entre Pánfilo y María, plantea Erasmo una situación similar a la que encontraremos en la Miscelánea: el diálogo en sí se presenta como forma refinada de cortejo, donde el coqueteo entre los interlocutores tiene un tono moderado mientras que las razones que llevan a una conclusión son lo más importante. El modelo femenino, como es previsible, también coincide: tanto en Erasmo como en Dávalos vemos a la dama inalcanzable, dura a los sentimientos del galán, desconfiando continuamente de sus profesiones de religión amorosa. Ambas, María y Cilena, responden a este tipo de declaraciones ironizando, $y$ devolviendo la conversación al cauce del debate. A pesar de que supuestamente el trato a la dama es amable y adorador, el empeño del galán Pánfilo se centra en convencer a María de que se case con él y para ello no duda en reducirla en la estima que de sí misma tenga la mujer y en devolverla didácticamente a su papel de consorte y complemento.

En otro coloquio, Mempsygamos, donde dialogan dos amigas, Olalla y Xantipe, Erasmo ponía en boca de Olalla el discurso más complaciente de la época: «considera [...] cuán poco vale la mujer apartada de su marido. La mayor honra que las matronas pueden tener es estar muy bien casadas con sus maridos. Esto muestra la ley natural en la flaqueza, vergüenza y encogimiento que en nosotros puso. Esto quiso Jesucristo, que la mujer totalmente esté a la gobernación del marido» (Erasmo, 2005, p. 84).

Más que en su discurso, que no se distancia tanto del erasmista, es en el trato a Cilena por parte de Delio (que a pesar de su rol magistral respecto a ella, en ningún momento la reprende ni llama a humildad) donde vemos la aportación de Dávalos a un modelo de pareja, que no coincide ya del todo con lo aprendido en sus lecturas, lo cual sería debido muy probablemente y en gran medida a la personalidad de Francisca.

Los coloquios de Dávalos van tejiendo y escenificando en las personas de sus interlocutores una imagen modélica -a lo Castiglione, podríamos decir con Luis Jaime Cisneros (1953) - del caballero y de la dama implicados en una relación amorosa, concebida ésta siempre como espacio de nobleza, sometido por lo tanto a rigurosas normas y a una compleja preceptiva ${ }^{2}$. El sostenido despliegue de cortesía de los interlocutores, a veces excesivamente engolada, está en profunda consonancia con la extensa exhibición de abolengo de Delio (como el coloquio XXXVIII, para alabanza de su origen y ancestros; o el XLII, donde llora a su hermano y lo muestra como el perfecto cortesano) y de Cilena (XL) y de saberes elegantes (a que se dedican por ejemplo los coloquios XIV y XV, sobre el origen de la música, la caballería y el caballo) ${ }^{3}$.

Delio y Cilena inician su diálogo de amor tratando las señales físicas del amador y por curiosidad de Cilena, también de las damas amadas (obsérvese que el amador es singular y las amadas plural), llevando el tópico de la enfermedad del amor y sus remedia («ahora se sigue que veamos si tiene remedio alguno el amor», VII, p. 29) hacia el trazado de una fisonomía propia del amante y reconociendo Delio ciertas señales que en las damas denotan «voluntad de ser amadas» (p. 26r). Se preocupan los interlocutores de cómo debe comportarse el amante (XIII): con discreción y secreto de los favores obtenidos, con modestia, con moderación en la mesa, el vino y las drogas, pues la temperancia es salud, e ilustran siempre con autoridades y ejemplos esta preceptiva; también tratan de cómo debe vestir el amante, "pulido y limpio», "conformándose con la ley, que obliga a huir la afeminada afectación» (XV, 60) y nos interesa especialmente que se diga cómo debe ser el gusto de las mujeres en cuanto a ello (60r).

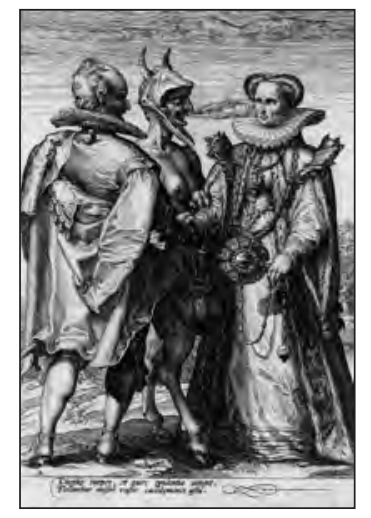

Hendrik Goltzius, El matrimonio de conveniencia (1595).

2

El amor no deja de «ser este privilegio del amante,/ de que carece el vulgo y torpe gente» (Coloquio IIII, p. 13); quedan excluidos los indios de la capacidad de amar, también: "no se pueda creer sean heridos de amorosa flecha, con diferencia alguna de las bestias» (XXXIIII, 154r).

3

Tal vez sea preciso leer esta profusión de signos aristocráticos en el contexto colonial como un reclamo de atención hacia la lejana metrópoli por parte de quienes se hallan en la periferia (Colombí, 2000). Para una distinción socioeconómica de los roles femeninos resulta muy interesante la mirada de José Antonio Maravall (1986).

\footnotetext{
Misoginia y defensa de las damas en el virreinato peruano: los coloquios entre Delio y Cilena en la Miscelánea Austral (1602) de Diego Dávalos

BEATRIZ BARRERA
} 


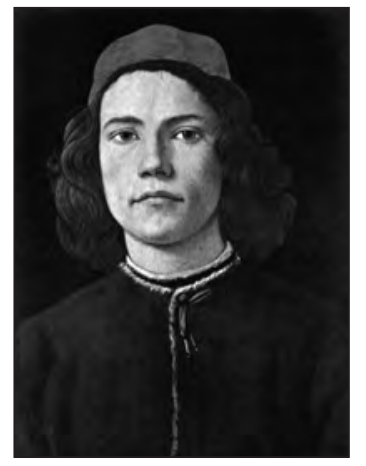

Sandro Botticelli, Retrato de joven (c. 1483).

4

La discrepancia es leve pero podría indicar un momento de participación real, directa, de Cilena en el discurso al manifestar una opinión que no favorece a Delio; habida cuenta de su bien documentada exposición en contra de los grandes, probablemente él fuera de baja estatura.

5

Vemos cómo el modelo de amante no es sino el modelo de cortesano en vigor y amante tan solo en cuanto que es el modelo que ha de procurar la mujer para que la ame.

6

La respuesta de Cilena es un poco sospechosa, siendo mujer de letras en el nivel que muestra su soneto, y más parece fruto de censura que continuidad de la conversación, pues a partir de ese momento ya no se habla de la mujer: "Discretísimamente dijeron todos, donde se prueba mi opinión, y se reprueba la condición de muchos, que por granjear nombre en la discreción, usan lenguajes descompuestos, juzgando que allí consiste gala, gracia y donaire. Y lo peor es que las más veces los tales por adornar sus dichos y acrecentar el crédito de sus empresas, incurren en el vicio, y detestable defecto del mentir, todo lo cual nace de falta de vergüenza» (74r).

7

La importancia dada a las joyas forma parte de un código social por el cual la riqueza del marido se expresaba en el adorno de su esposa.

Misoginia y defensa de las damas en el virreinato peruano: los coloquios entre Delio y Cilena en la Miscelánea Austral (1602) de Diego Dávalos

BEATRIZ BARRERA
Se consideran otros requisitos que ayudan a hacer del caballero un buen amante, como el conocimiento de idiomas ( ser de agradable y discreta conversación, la cual se ve pocas veces en quien no tiene alguna ciencia, o no sabe más que la lengua materna», XV, 61r), que sea manso y sufrido (XVI, 62), que no sea avariento (62), que ame las ciencias (62r), que tenga un bello rostro y una complexión fuerte (63r). Mientras que Delio piensa que la pequeña disposición favorece a la inteligencia, Cilena parece inclinarse a la alta estatura pero tras las razones de Delio concluye que la mediana estatura es la mejor $(63 \mathrm{r})^{4}$.

Las características que la dama debe buscar en su amante abarcan ámbitos distantes entre sí, pero los interlocutores se mueven de uno a otro con soltura: debe ocuparse de letras (XVII, 67r); llevar vida ordenada (69), lo que excluye la ambición y valida el comedimiento; afabilidad, urbanidad (72r) y vergüenza, son rasgos positivos que adornan al amante al hacerlo sociable 5 .

El asunto de la vergüenza llama la atención de Cilena, que apunta: «Aunque es propio del hombre la vergüenza, lo es mucho más en la mujer por ser don de que con tan larga mano naturaleza la dotó» Y Delio se explaya:

eso es de manera, y es tan necesaria en ellas, que dijo un sabio, si en la mujer no hubiera de haber más que una parte buena, de necesidad había de ser la vergüenza. Y otro dijo: en la mujer vergonzosa poco hay que reprender, y en la deshonesta, nada que alabar. Y Platón dijo: si las mujeres pudiesen ver con ojos corporales cuánta es la belleza del alma vergonzosa, jamás habría mujer deshonesta. Y San Jerónimo dice que a los hombres les es lícito buscar honra y gloria, por muchas vías y modos, como son armas y letras con las semejantes, y a la mujer con la sola vergüenza, y con ella se hace eterna en estimación (XIX, 74)6.

Hacen valioso al amante la cortesía, el decoro, usar juegos conforme a su edad y no perderse en ellos (76), inmortalizar a sus amadas con poemas, amar a la patria como nobleza obliga y entender de joyas (XIX, 77r) ${ }^{7}$.

El tema de la mujer en la Miscelánea adquiere mayor protagonismo poco a poco, vinculado a la casuística amorosa que aparece en los diez primeros coloquios (sobre la naturaleza del amor) y desde el XIII al XIX (planteados en torno a «las partes que debe tener el perfecto amante») pero se convertirá en el centro de la conversación en el XX, «donde se muestra la perfección que debe tener la dama, y la utilidad de su virtuosa ocupación» (79). Así al final del coloquio XIX se inicia por fin el debate sobre «lo que debe ser [una dama], no solo en belleza, mas en otras partes, que la esmalten, aunque es verdad (como ya habemos dicho) que para con los hombres no importan las aventajadas perfecciones, ni por eso son más queridas ni más estimadas», en decir de Cilena (78).

El coloquio XX desarrolla este argumento, comenzando Delio, muy neoplatónico, por lo más importante: la hermosura de facciones y demás proporción de la dama, considerando que «la belleza no es otra cosa más que en cierto modo un resplandor de la divina [...]. Con esto debe tener gracia en el hablar, y entretener con diversidad de razones». La respuesta de Cilena no parece redactada por su esposo, por sofisticada y por el interés personal que encierra, ya que remite tanto a su pragmática individual como a su educación en la corte y conocimiento de la urbanidad del medio aúlico:

Lo principal (a mi parecer) es que tenga altivez en su estimación, porque en esto no puede haber extremo que dañe, antes bien es causa de muchos bienes, fáciles de entender y largos de referir. El rostro modesto, ojos bajos, huyendo las ocasiones de que se le pierda el respeto, no sólo con ella hablando, mas en su presencia no debe sufrir que se oiga palabra descompuesta; y si alguna lo fuere, debe responder con mesura, tomándola como si a diferente intento se hubiese dicho. Debe así mismo tener afabilidad compuesta y grave, que parezca natural (79).

Delio ataca a las que «alegremente acogen, reciben y saludan, mas con tal lenguaje que el que las visita y habla, va tan pagado que cree de su firmeza más facilidad de la que es bien se presuma»; también a las que "para mostrarse discretas, andan a mendigar términos y vocablos nuevos, con cuya impropiedad destruyen el ornato que han procurado». Cilena, segura de su elocuencia y continuando un discurso anterior donde ironizaba al manifestar su preferencia de que el amante fuera mudo, dice que «no es menos el extremo en que otros [sic] dan, transformándose en estatuas mudas de mármol, pues en todo un día no mueven los labios para hablar y quieren se crea nace de puridad de ánimo este silencio, siendo el 
excesivo hijo de la ignorancia» (79)8. Y sigue Delio: «Mayor es el yerro de las que por mostrarse graciosas, y de agudos dichos, discurren en modo meretricio, cosa impropia aun en los hombres (como ya dijimos) y en las mujeres digna de afear, porque ninguna agrada más que la honesta. En prueba de lo cual, afirma Aristóteles, que por esta parte más que por otra se prenden y ligan los hombres de amor [...] ni hombre ni mujer puede tener belleza en el rostro si en él no manifiesta honestidad» (79r) Cilena: «Y muchos han dicho que no hay más belleza que la misma honestidad y vergüenza». Honestidad y vergüenza son pues deseables, si no en igual medida, sí en la misma calidad, para hombres y mujeres. Otras cualidades de la dama deben ser: afabilidad, elegancia, compostura, discreción (79r).

$\mathrm{El}$ asunto de los celos, que tanto interesa a Dávalos, se trató para los caballeros anteriormente con una fuerte ilustración literaria. Para el caso femenino, el consejo es directo y recuerda lo anteriormente acordado: la dama «no debe dar ocasión a su amante de sospecha de celos» (80) y asegura Cilena que «en esa culpa nunca cae la dama de dignas partes y calidades», como tampoco debería caer en dolerse de los celos del amante ni mostrar piedad a sus lágrimas, pues «como en las mujeres sola una sospecha les causa mácula, privándolas de su buena fama, es bien mirarlo todo, porque les importa el buen crédito más que la vida» (80).

La honra es principal para Cilena, que desconfía de la discreción masculina y avisa de que mejor ser «notadas de crueles que alabadas de piadosas» y aprovecha el momento para advertir a las damas contra la pérdida de su honra, centro de gravedad permanente de la posición de la mujer en la sociedad:

oh, señoras, no os induzca un placer tan de poco momento como el de ser servidas, a mil eternos dolores que en él se esconden. Ni os duela dejar y perder lo que por causa tan breve falta, olvidando lo permaneciente, que es la fama, por tan poca y falsa ganancia. ¿Cuál amante jamás se halló, que en el semblante, en palabras, y en promesas no mostrase amar? Finge arder en el deseo, y en la voluntad apenas se calienta, jura alguno que en fuego perece, cuyo corazón en hielo reposa. Y cuanto más con agudas razones esto, o su semejante se diga o escriba, menos se debe creer [...] Y menos creáis los encarecimientos que de belleza os intimaren, porque todo es general y común estilo para con todas aprendido y decorado (80r-81).
La advertencia contra los hombres es parte importante del discurso de Cilena, quien se expresa así primero desde su circunstancia concreta y presente, al ser cortejada por Delio, y después en términos generales a modo de arte de amar para damas'. En el Coloquio XX Delio sugiere a Cilena que muestre a su dama (la lectora que recibe sus consejos) «que sepa conocer cuando es amada, sin pagarse ni satisfacerse de solos pasos y demostraciones de ansias» (81r) y ella se remite a Ovidio: «No solo no debe fiar en ello, ni aun en graves juramentos, porque todos os valéis de lo que Ovidio dice, que se ríe Júpiter de los juramentos de los amantes, para no ofenderse de ellos. Con lo cual mintiendo, juráis licenciosamente» (81r).

Por otra parte, la extensa respuesta de Cilena a la pregunta de «cómo será bien que la dama se aderece y adorne» nos proyecta a un universo tan poco viril para los hombres de su tiempo que cuesta imaginar que no la haya dado Francisca:

En eso no puede haber preceptos, por la fuerza que el uso tiene, mas débese vestir siempre al más moderno, limitando o alargando lo que más le convenga a su rostro y cuerpo y nunca descuidarse en andar bien tratada, porque ninguna cosa es tan conveniente a su profesión como el cuidadoso ornato y compostura, de lo cual ya habemos tratado, hablando del amante (82).

La palabra profesión aquí nos remite al significado de modo y hasta medio de vida de una persona. Que Cilena aparezca como una dama profesional nos parece sumamente ilustrativo. Hay un lugar social para la mujer en tanto sea respetada y en tanto cumpla con unas normas de decoro, es lo que expresa el discurso de Cilena, y es de una gran lucidez histórica y sentido de la realidad si lo comparamos con las entelequias científico-morales sobre la mujer (sin distinción de estamento social) procedentes de la herencia cultural que elaboraran filósofos, poetas y eclesiásticos.

Cilena, en un alarde de dominio de la estética práctica y las tendencias de la moda aristocrática, demuestra conocer bien su profesión, pues. A la pregunta de cuáles son los colores propios a una dama «que de serlo se precia» responde así: "Bien parece en la florida juventud todo género de ellos, bien matizados, y así mismo oro, plata y ricas

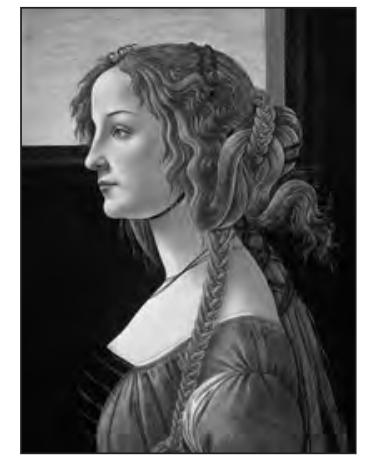

La dama petrarquista. Sandro Botticelli, Retrato de Simonetta Vespucci (v. 1476-1480).

8

Cuando Cilena en vez de seguir hablando en femenino se refiere al extremo en que otros dan, con su empleo del masculino plural está ampliando el discurso y volviéndolo al cauce de la cortesía antes que al de la distinción sexual.

9

La primera vez que manifiesta este topos es tras el primer soneto con que la agasaja Delio: "ay hombres, y cuán bien sabéis significar lo que no sentís, y cuántas prisiones, y estragos de amor sin amar, porque no llamo yo amor, ni afición, la que hace a los hombres manifestar ansias, que si las tuviesen tan ardientes, como dicen, no las sabrían tan bien adornar» (II, 4), escena que se repite, como en la celebración de Cilena en un poema de Delio al que ella responde que él, como poeta, finge (122).

\footnotetext{
Misoginia y defensa de las damas en el virreinato peruano: los coloquios entre Delio y Cilena en la Miscelánea Austral (1602) de Diego Dávalos

BEATRIZ BARRERA
} 
10

Los interlocutores masculinos no suelen aceptar una victoria dialéctica en los coloquios de este tipo, lo que nos recuerda una vez más que no es la Miscelánea una obra didáctica de adoctrinamiento de mujeres como otros diálogos.
Misoginia y defensa de las damas en el virreinato peruano: los coloquios entre Delio y Cilena en la Miscelánea Austral (1602) de Diego Dávalos

BEATRIZ BARRERA joyas, pero lo que más ordinario suele estar bien a las hermosas es lo negro, y cuando de esto se quiera mudar, servirá lo blanco, rosado, columbino, y otros colores exquisitos. Advirtiendo en el hacer elección al que más ajuste con su rostro y color» (82). Y desde su afianzado conocimiento del medio desafía la autoridad de Ovidio con una voz que no se parece a la que le presta otras veces su marido:

paréceme que supo más Ovidio de transformaciones y fábulas que de adornar y componer damas, porque es error manifiesto decir que a la morena convenga lo blanco, pues antes con él descubre más su defecto, como opuesto de su color natural y si a la blanca le está bien lo negro, es porque allí resplandece más la blancura, con lo cual todo conforma, ajusta y matiza bien (82).

Observamos que el criterio de belleza es conforme a convenciones sociales: la piel oscura está desacreditada frente al monopolio de la blanca. Delio trata de lucirse inútilmente con una teoría de colores en el vestir según los temperamentos pero la respuesta de Cilena regresa bruscamente al prejuicio racial: «A eso no sé responder, porque como no me guío por filosofía ignoro los efectos y sus causas. Solo vuelvo a afirmarme en que a la blanca todos los colores le están, asientan y parecen bien, y a la morena casi todos mal» (82r). De lo que se sigue una crítica del maquillaje por parte de Delio y una defensa de su uso cuando es moderado por parte de Cilena, pero ella quiere volver a las perfecciones que debe tener la dama y más que lo físico y el maquillaje es importante su conversación: «agudos dichos y sentenciosos conceptos» (82r). Si atendemos a la fama de Cilena, cuya elocuencia parece ser su cualidad más característica (XXVIII, 121r), la reclamación que hace concuerda con el personaje y nos acerca una vez más a la idea de una personalidad real que se proyecta, en algunos momentos se diría que sin intermediarios, en un discurso distinto del de su interlocutor.

La última de las cuestiones que aborda la Primera Parte de la Miscelánea en torno a la dialéctica entre hombre y mujer es su diferente modo de amar. Cilena cree «que es tan propio en los hombres el fingirlo [el amor] como en las mujeres ocultarlo, y si os parece quede por resolución que el fingirlo sea posible en poco tiempo, y que para disimularlo, el poco sea mucho» (XXII, 89r-90). A la pregunta de Cilena de si «Más ama la mujer tímida o la atrevida», responde Delio que la atrevida, "porque en mujer naturalmente no puede haber atrevimiento, si no es nacido y causado de amor, y es forzoso que sea grande, cuando el limitado ánimo femenil sale de su naturaleza» (XXII, 90r); de lo que discrepa Cilena, y no con exposición de razones objetivas o autoridades, sino empleando un verbo que la proyecta como sujeto directo de la experiencia antes que como intermediario de un pensamiento general, el verbo sentir, que remite a su opinión individual:

Yo siento al contrario, porque la pregunta no dice, ni trata de la atrevida por amor, sino de la naturalmente orgullosa, que aunque en la mujer no es natural el brío, unas lo muestran más que otras, [...] y no hay duda sino que la tímida ame más, a lo menos débese presumir grande exceso de amor, el que le hiciere manifestarlo, sacándola de su natural curso, que en cuanto a la fuerza del amor, tanto se puede mostrar en la una como en la otra [...].

Delio ante la exposición de Cilena responde: «Razones son estas que me hacen conocer lo bien que me está callar, y dejar esta contienda y duda para quien tenga más desocupado el entendimiento que yo» $(90 \mathrm{r})^{10}$.

A la cuestión de quién es naturalmente más constante en el amor, hombre o mujer, Delio responde que «cierto está que lo será el hombre, como más perfecto en todas sus obras» y remite a San Basilio, pero Cilena declara tener una opinión contraria a la de tal autor, por lo que no puede defender su propio punto de vista, pero sí citar lo que dicen algunos filósofos que ha leído:

que por ser el hombre de más colérica calidad, ama con más repentino hervor, mostrando luego vehemente y grande amor, pero que este dura menos, como cosa violenta, mas que la mujer como más fría no recibe tan presto el ardiente afecto y así tarda más en resfriarse, una vez siendo encendido [...] y yo digo que la mujer es como la oliva, que aunque tarda en dar fruto, permanece largos tiempos, ofreciendo siempre más. Y aunque esto no sea así, y se haya de estar a lo que habéis alegado, digo que el varón ha estragado esa perfección en que Dios le crió, usando del amor viciosamente, con lo cual no puede tener en él firmeza. Ved cómo se podría gloriar de constante. Lo cual puede hacer la mujer, porque su presunción y natural honestidad le hace no ser mudable (91). 
Reconocemos el trasfondo científico de la diferencia de temperatura como fundamento de la diferencia sexual, pero encontramos invertido su significado habitual para favorecer moralmente la naturaleza de la mujer.

La siguiente pregunta es "Quién ama más y quién se persuade más a que es amado» y aquí el ataque de Cilena a los hombres es frontal: «Son los hombres tan jactanciosos y soberbios que siempre se figuran dignos de todo honor, méritos y exenciones, y así no solo con causa, mas aun sin ellas se suelen tener por amados, y aun lo suelen publicar, sin considerar daño y ofensa que hacen a los inocentes» (XXII, 91r). Ante la agresividad que manifiesta Cilena, el diálogo se aleja de la controversia presente y deriva a otros lugares.

Después de discurrir las conversaciones por variados temas que poca o ninguna relación tienen con el amor o sus afectados, en el último coloquio, el XLIIII, se regresa al problema femenino. Delio muestra a Cilena su traducción de unos sonetos de Victoria Colona (217r), su pariente, y de la admiración de su excelencia resurge en el diálogo el tema de la maledicencia contra el linaje mujeril: «con exceso apasionado hasta conseguir sus intentos, a lo cual afirma les ayuda la flaqueza natural, así de fuerzas como de entendimiento». Cilena responde aquí: «A fe que diga, la [mujer] mala o la deshonesta» y ante la acusación de «ser la mujer poderosa incitación para depravar al marido» ilustrada por Delio, inicia una larga queja seguida de una defensa:

¿por qué son tan culpadas esas mujeres que ayudaron a los herejes referidos, no siendo ellas principales en esa culpa. Y no se abomina (como es razón y el caso lo pide) de esos dogmatizadores y maestros suyos? cuyos semejantes en tales errores ha habido otros muchos que no se ayudaron de mujeres, sino de hombres. Y si queremos hallar lo cierto, conoceremos de muchos casos graves haber sido descubiertos por mujeres, a tiempo que se remediaron sus daños y se apagaron sus incendios $(217 \mathrm{r}, 218)$.

Continúa Cilena citando autoridades a favor de la participación de las mujeres en la esfera pública. Para Delio, «muchos de los maledicientes de mujeres lo hicieron y hacen más por mostrarse agudos que por sentir justicia en sus opiniones y palabras». El coloquio desarrolla aún el asunto hasta desembocar en la introducción de la Defensa de damas, que Delio promete mostrarle a Cilena el día siguiente y así se llega al fin abierto de la Miscelánea.

\section{Algunas consideraciones en torno al texto y su autoría}

Nos gustaría llamar la atención sobre unas palabras de Diego Dávalos en la presentación de su obra, de las que ha partido un planteamiento que queremos compartir sobre la autoría de la misma:

Quien algo quisiese ser, emprenda cosas que le den nombre. Por todo lo cual me moví y determiné a poner en escrito los coloquios que pasamos mi amada y amante esposa y yo, después de haber merecido el tesoro y gloria de poseerla, refiriéndolos según y como pasaron los años que yo a tan alta empresa aspiraba [...]. Púsele [a la dama de los coloquios] el nombre de Cilena, de que hice elección por el Dios de la elocuencia, que es Cileno, a quien no sólo imita, pero iguala; siendo el propio suyo doña Francisca de Briviesca y Arellano, cuya prosapia es bien conocida en nuestra España («Al lector», Prólogo de la Primera Parte de la Miscelánea Austral).

Los poemas que preceden a la Miscelánea no siempre están dedicados al autor, Diego Dávalos, sino que ocho de los quince que arropan los coloquios están dedicados a Delio y Cilena conjuntamente y los otros siete a Delio o bien a Diego Dávalos. El poeta declara a los lectores que espera ser envidiado por «el singular talento que por muchas razones, sentencias y dudas manifiesta mi Cilena; las cuales no son fingidas (aunque parezcan nuevas en mujer) antes cercenadas en su mucha agudeza». La singularidad de Francisca es presentada desde sus dotes literarias: elocuencia, inteligencia y erudición, propias de varones todavía incluso para ese grupo de mentalidad moderna que parecen haber sido los poetas antárticos. Estas cualidades hacen de ella una interlocutora privilegiada, sobradamente acreditada en cuestiones poéticas.

Es suyo, de hecho, el primero de los sonetos («De Cilena a Delio») que encontramos en la Miscelánea, y que, como apunta Alicia de Colombí, tal vez sea el de mayor calidad de los que presentan la obra de Dávalos:

¿Cuál fuerza inexpugnable, o duro freno

En potestad de brazo poderoso,

Podrá oponerse al curso presuroso

Del tiempo esquivo de mudanzas lleno?

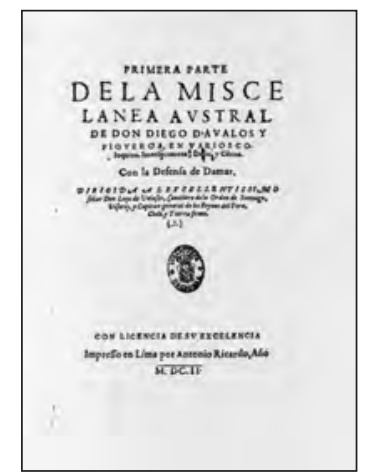

Portada de la Miscelánea Austral de Diego Dávalos (Lima, 1602).

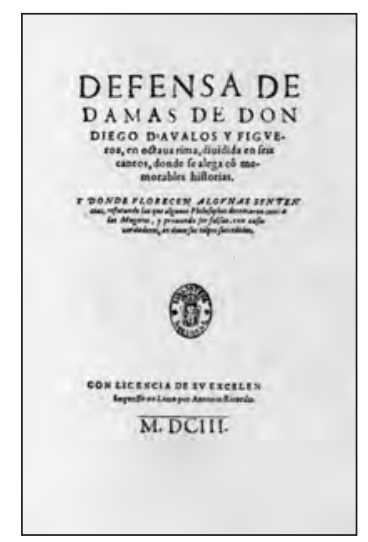

Portada de la Defensa de damas de Diego Dávalos (Lima, 1603).

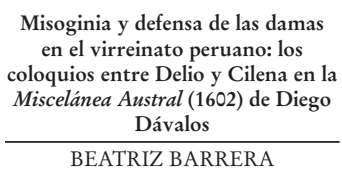


11

Este soneto sirve a Alicia de Colombí (2003) para proponer a Francisca de Briviesca como la primera mujer poeta del virreinato pervano. Coincidimos en casi toda su lectura del poema y también en desatender la exótica propuesta de "mixtificación» inducida por Javier Cheesman Jiménez y otros, según la cual Cilena habría sido un desdoblamiento del autor bajo una máscara femenina. No solamente nos parece indiscutible la presencia de Doña Francisca bajo el nombre de Cilena, sino que consideramos seriamente la posibilidad de su participación activa en la obra.

12

Las mismas, con algún matiz añadido, que recupera e Diccionario de autoridades, RAEA 1729 p. 568,1 . Nuestra búsqueda en el CORDE: REAL ACADEMIA ESPAÑOLA: Banco de datos (CORDE) [en línea]. Corpus diacrónico del español. <http://www.rae.es> [25/05/2010], limitada al periodo comprendido entre 1590 y 1610, arrojó el resultado de 76 casos en 44 documentos, de donde extrajimos las conclusiones que presentamos.

13

O bien en otro contexto más distanciado de lo anterior nos referimos al contraste de las piedras y metales preciosos: su pesado y medida para una justa valoración mercantil. "Contraste» designaba la actividad de apreciar minerales tanto como el oficio, la persona que lo desempeñaba y el lugar donde se realizaba. Entendemos que aquí, vinculado el contraste al daño son las dos primeras significaciones las pertinentes.

14

De nuevo remitimos al Corpus Diacrónico del Español (CORDE) para leer adecuadamente la expresión "en su nombre». Encontramos dieciocho empleos de ese mismo sintagma en ocho documentos, solamente en documentos de los años 1602 y 1603.

\footnotetext{
Misoginia y defensa de las damas en el virreinato peruano: los coloquios entre Delio y Cilena en la Miscelánea Austral (1602) de Diego Dávalos

BEATRIZ BARRERA
}

Su vuelo muestra al parecer sereno,

Manso agradable, dulce, y deleitoso;

Un móvil siendo rapto, y riguroso,

De todas vidas el mayor veneno:

Es un fuerte ministro de la muerte,

De ilustres obras tenebroso nido,

De alegre vista, y manifiesto engaño:

Mas triunfa dél con alta y rara suerte

Delio en su canto, y del voraz olvido;

$Y$ yo en su nombre sin contraste, o daño ${ }^{11}$.

El último verso nos resulta revelador de hasta qué punto la dama se reconoce partícipe de la Miscelánea: si Delio triunfa con su canto sobre el tiempo (y por ende sobre la muerte y sobre el olvido que todo devora) también ella está inmortalizada en el nombre poético de su marido (es decir, en su fama), sin que ello le suponga "contraste o daño", sin que le ofenda ni perjudique; o tal vez sin que su propio triunfo sea una contrariedad para el del marido.

La palabra «contraste» resulta en este contexto muy interesante porque puede estar siendo empleada a un tiempo literal y metafóricamente. Puede significar un viento antes favorable que se ha vuelto repentinamente adverso (en rica consonancia con el curso o vuelo presuroso en que se materializa el tiempo en la primera parte del poema) o también enfrentamiento, oposición, impedimento o contienda, lo que concuerda muy bien con la idea del daño en que concluye el verso. A finales del siglo XVI y principios del XVII encontramos el vocablo «contraste» documentado con al menos tres acepciones $^{12}$. El uso de la palabra remite como hemos mencionado al viento o en general a una adversidad u obstáculo, a la resistencia que opone el medio a una acción; también al encuentro o combate entre opuestos, es decir, a una contienda ${ }^{13}$.

Cuando Cilena declara estar triunfando en el «nombre» conseguido por Delio, ella también, sobre el olvido, podríamos quedar tranquilos asumiendo que una mujer de su época sienta que la inmortalizan sin ella producir nada, pero no sería demasiado disparatado entender que pudiera haber colaborado en la confección de la obra más allá de inspirarla ${ }^{14}$. La expresión de Cilena («en su nombre») tenía por lo general el mismo uso que seguimos manteniendo: hacer algo en nombre de alguien es actuar haciendo uso de su autoridad y con el mismo efecto que si lo hiciera esa persona; sin embargo hemos encontrado también, y en un contexto de preceptiva poética, que puede usarse el sintagma con otro significado, y con ello podría estar jugando Cilena. Luis Alfonso de Carvallo en su Cisne de Apolo (1602) se expresaba así (la cursiva es nuestra):

Dramática poesía es aquella que los latinos llaman activa, imitativa o representativa, en la cual nunca el Poeta habla en su nombre, pero induce o introduce personas que hablen y representen el mismo caso, de cuyo género de poesía son las comedias, tragedias, coloquios, diálogos y algunas églogas. Exagemática poesía es la que en latín llaman narrativa, y en ella sólo habla el Poeta en su nombre, en cuyo género se cuentan los libros y artes que enseñan alguna cosa, como es la Poética de Horacio, el Arte de amar de Ovidio, las Geórgicas de Virgilio y otras poesías semejantes. La mista poesía es compuesta destas dos, dramática y exagemática, se puede llamar común. En la cual el Poeta ya habla por sí y de su parte, y ya introduciendo un razonamiento dicho por tercera persona, que llaman prosopopeya, como es muy ordinario en las historias (Carvallo, 1997, p. 254).

En el mismo libro, poco después, encontramos: «En el estilo mixto se comprehende la Historia, porque en ella habla el Poeta, ya en su nombre, dando cuenta de los ajenos subcesos, y ya en nombre de otro, como el segundo de los Eneidos de Vergilio, que comienza hablar el Poeta significando el silencio y luego cuenta en persona de Eneas la destruición de Troya» (Carvallo, 1997, p. 274).

Cilena podría haber utilizado en sus versos cualquier expresión que la incluyera como imagen, como objeto que aparece en el interior del texto; podría haber dicho «y yo en su obra» o "y yo en su triunfo» en vez de «y yo en su nombre»; pero no es así, lo que parece indicar es que triunfa ella también en o con o hasta bajo el nombre de Delio y su afirmación (nótese que está en el último verso, concluyendo el soneto) remite a la posición de la autoría, que se completa con lo que pudiera ser una declaración del amor más allá de la frustración o la envidia («sin contraste o daño»), sentimientos mezquinos esos, que no han lugar en el seno de un matrimonio noble y bien avenido como el que ellos exponen; un motivo razonable, podríamos pensar, por el cual la «discretísima» 
(es su epíteto) Cilena no demandaría más reconocimiento que el que reclamase en este verso y se inclina a justificar el atrevimiento de haber sugerido que su eternidad fue ganada además de merecida.

Partiendo de esta interpretación, podrían cobrar un sentido más allá de lo protocolario algunas de las alusiones a Cilena que extraemos de los poemas preliminares de la Miscelánea. Si en el soneto del general Don Fernando de Córdova a Delio y Cilena, Cilena es «el instrumento que recobra [...] el Lauro» y tiene la función de admirar y coronar a un Delio nuevamente solar en el centro de un cielo estrellado ( mirado por Cilena en su Elicona, / Phebo de nuestro siglo, que corona / a Delio aplica»); en cambio en el de Don Diego de Carvajal se requiere reconocimiento para la dama: la Miscelánea aparece como «depósito del Néctar de escritores», producto del ingenio de Delio «que es colmena», pero concluye con una reclamación galante: «Mas porque restituyas los favores / A cuyos son, confiesa que Cilena / en toda esta labor te da las Flores».

El soneto del almirante don Lorenzo Fernández de Heredia atribuye igual mérito a ambos interlocutores cuando en su último terceto el ingenio «en la cima ilustre de Cilena / Y del sublime Delio, de tal salto, / Eleva el alma, y roba los sentidos». Bartolomé de Acuña concuerda en intención y en galantería cuando escribe que «la Antártica región eternizada / del generoso Delio, y su Cilena» será más envidiada de lo que lo fue España: «Consiste la razón de aquesta pena / en que, por ser Cilena celebrada, / La envidia, y tiempo están en su cadena». Pedro de Oña equipara los dones de Naturaleza y Fortuna al autor («entendido por el nombre de Delio»): si la primera le dio nobleza de sangre e ingenio, la segunda lo dotó «no menos que de Cilena», a la que dice «mas tanto Cilena vales, que tú sola en la segunda haces los votos iguales».

El licenciado Antonio Maldonado de Silva no parece dispuesto a apreciar a la dama si no es a la sombra (más bien a la luz) de su esposo: «Delio Sol del suelo / ciencia influye, y su Cilena / Deste resplandor tan llena / como la luna del cielo. / Que no es impropio se ilustre / Con resplandor tan crecido, / Pues los rayos del marido / En ella son propio lustre.» Para él la presencia de Cilena era precisa a la Miscelánea y compara el «fruto perfecto» de la unión de Delio (el sol) y Cilena (su luna) al de la palma «que es más fértil y abundante» si «con la hembra / en breve trecho se siembra, /que por sí sola, y distante»; se despide humildemente abundando en su hallazgo metafórico y pidiendo disculpas al compararse a sí mismo con «la tierra importuna / interpuesta al Sol y Luna» antes de retirarse.

«Un religioso grave» observa en su poema que «no estaba aún hasta aquí el Pirú en su punto; / con el tesoro vil de Plutón solo, / Sin dar Minerva el suyo al Austral Polo» y «ya (gloria de Dios) lo influye todo junto, / con Cilena, y con Delio el noble Apolo». Aquí Cilena podría implícitamente estar funcionando como una prolongación de la antigua Minerva en paralelo con el relevo de Apolo que se atribuye una y otra vez a su marido; situación que se repite en el soneto del licenciado Francisco Núñez de Bonilla «a Delio y Cilena», donde se hace asomar allá en Oriente a Delio Divino, «con Palma en mano y Lauro en la cabeza, "sobre carro triunfal de industria rara» al modo de Petrarca; y bien rara resulta su industria, efectivamente, ya que roza la parodia por su atrevimiento: Delio viene, «tirado en esta máquina superba / no por el desigual humilde huello / de cisnes del Menandro, ni palomas, / Sino del mismo Apolo y de Minerva, / que vienen paso a paso ufanos d'ello» ${ }^{15}$.

Si nos preguntáramos por qué, de haber participado ambos cónyuges en la composición de la obra, como parece haber sucedido, se decidió Diego Dávalos a firmarla en solitario, aun conociendo los amigos del entorno más cercano la importancia de la dama para el libro, todas las hipótesis apuntarían en una misma dirección: es tan infrecuente en mujer el talento de Cilena y tan envidiable, y es tan delicado el asunto del amor y de lo que conviene a las damas, más viniendo de conciencia femenina, que no parecería oportuno ni honroso para el marido exponer a su esposa a críticas y censuras innecesarias, por unas opiniones que por lo general ambos compartían y que ella tal vez habría tenido que justificar extraliterariamente en mayor medida que él. Acaso bajo un nombre de varón y vigilando («cercenando», dijo) la elocuencia de su esposa, la estaría Dávalos protegiendo de un público misógino y del desconcierto de tener que atenerse a un protocolo inexistente para mujeres de alto rango social que sean coautoras de misceláneas.
15

El vicerrector de la Ciudad de los Reyes debió divertirse mucho poniendo a los dioses clásicos a tirar de un carro; sin embargo no es eso lo que nos ha llamado más la atención, sino el juego de los amigos indianos con ese paralelismo implícito que hace que Delio y Cilena sean ya los nuevos Apolo y Minerva en más de una ocasión. Nos preguntamos si habrían ido tan lejos de hallarse en la Península. 


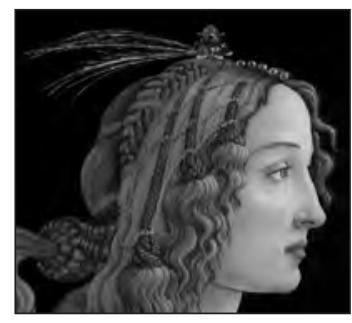

Sandro Botticelli, Retrato de Simonetta Vespucci (c. 1474).

\section{Bibliografía}

Archer, Robert (2001), Misoginia y defensa de las mujeres, Madrid, Cátedra (Colección Feminismos). Universitat de València. Instituto de la Mujer.

Barrera, Beatriz (2008), «Una Defensa de Damas (1603) en la Academia Antártica. Diego Dávalos y el debate sobre el matrimonio", en Herencia cultural de España en América. Siglos XVII y XVIII (ed. Trinidad Barrera), Madrid / Frankfurt, Iberoamericana /Vervuert, pp. 69-84.

Carvallo, Luis Alfonso de (1997), Cisne de Apolo (Ed. Alberto Porqueras Mayo), Kassel, Reichenberger.

Cisneros, Luis Jaime (1953), "Castiglione y la Defensa de Damas", Mercurio Peruano, 34:310-321, pp. 540-543.

Colombí, Alicia de (1985), Petrarquismo peruano: Diego Dávalos y la Miscelánea Austral, Londres, Támesis Books.

Colombí, Alicia de (2000), «Erudición humanista en saber omnicomprensivo e identidad colonial», en Karl Kohut y Sonia Rose (eds.), La formación de la cultura virreinal. I. La etapa inicial, Frankfurt/Madrid, Vervuert/Iberoamericana, pp. 75-91.

Colombí-Monguió, Alicia de (2003), «Doña Francisca de Briviesca y Arellano: la primera mujer poeta de Los Charcas» (en el índice del volumen en vez de Los Charcas se dice «de Perú»), en Del Exe Antiguo A Nuestro Nuevo Polo: Una década de lírica virreinal (Charcas, 1602-1612), Ann
Arbor, Michigan, CELACP / Iberoamericana Editores, pp. 67-81.

Dávalos y Figueroa, Diego (1602), Primera Parte de la Miscelánea Austral, en Textos clásicos de poesía virreinal (2001) (ed. Antonio Lorente), Madrid, Colección Clásicos Tavera (CD-ROM).

Dávalos y Figueroa, Diego (1603), Defensa de damas, en Textos clásicos de poesía virreinal (2001) (ed. Antonio Lorente), Madrid, Colección Clásicos Tavera (CD-ROM).

Erasmo de Rotterdam (2005), Coloquios familiares. Edición de Alfonso Ruiz de Virués (Ed. Andrea Herrán y Modesto Santos), Barcelona, Anthropos.

Gómez, Jesús (1988), El diálogo en el renacimiento español, Madrid, Cátedra, 1988.

Maravall, José Antonio (1986), «La tensión hombre-mujer», cap. XIII de La literatura picaresca desde la historia social (siglos XVI y XVII), Madrid, Taurus, pp. 639-697.

Isabel Morant (2002), Discursos de la vida buena. Matrimonio, Mujer y Sexualidad en la Literatura Humanista, Madrid, Cátedra.

Morant, Isabel (2006), «Hombres y mujeres en el discurso de los moralistas. Funciones y relaciones», en Isabel Morant, Isabel (dir.), Historia de las mujeres en España y América Latina (El mundo moderno), Vol. II, Madrid, Cátedra, pp. 27-61.

Rallo Gruss, Asunción (1996), La escritura dialéctica. Estudios sobre el diálogo renacentista, Málaga, Universidad de Málaga.
Misoginia y defensa de las dama en el virreinato peruano: los coloquios entre Delio y Cilena en 1 Miscelánea Austral (1602) de Diego Dávalos

BEATRIZ BARRERA 